\title{
FOCAL CONTRACTURE FOLLOWING INJECTION OF SUCCINYLCHOLINE IN PATIENTS WITH PERIPHERAL NERVE INJURY
}

\author{
Chingmuh Lee, Elaine Yang, and Ronald L. Katz
}

\begin{abstract}
FOCAL MUSCLE CONTRACTURE in the denervated limb following systemic intravenous injection of succinylcholine has been experimentally demonstrated ${ }^{1}$ but rarely observed clinically in patients with peripheral nerve injury. ${ }^{2-4}$ In the past two years we have observed focal contracture in the wrist and the hand following use of succinylcholine to facilitate intubation of the trachea in three patients, one with recent nerve injury, another with chronic nerve injury, and the third with subclinical nerve injury. The report is intended to add to the understanding of the occurrence and the time course of this well-known but clinically rarely documented neurological condition.
\end{abstract}

\section{CASE REPORTS}

Case 1. A 66-year-old $70 \mathrm{~kg}$ male was admitted for aortobifemoral arterial bypass graft. The patient had a long-standing history of arteriosclerotic disease, and ten years before admission had a left renal artery endarterectomy which cured his severe hypertension and associated congestive heart failure.

Thirty days prior to admission he underwent an aortogram through the left axillary artery for evaluation of the carotid as well as the femoral circulations. As a complication of the procedure he suffered a compression of the left brachial plexus and the left axillary artery by a blood clot of three days' duration. This was removed under local analgesia and, at the same time, the axillary artery was also explored.

The residual damage from the brachial plexus compression consisted of his left hand still being numb and feeling as if it was tightly wrapped. The left palm remained anaesthetic to cold, markedly hypaesthetic to pin-prick and to touch along the median nerve distribution, and slightly hypaesthetic to pin-prick along the ulnar and the radial nerve distributions. His grip in the left hand was weak but had no limitation of range of motion or visible loss of muscle mass. The circulation to the hand was adequate, and there were no signs of local sympathetic dysfunction.

Following oxygenation, and two minutes after d-tubocurarine $3 \mathrm{mg}$, succinylcholine $100 \mathrm{mg}$ was injected intravenously. Fasciculations were transient and

Chingmuh Lee, M.D., Associate Professor-in-Residence; Elaine Yang, M.D., Fellow; Ronald L. Katz, M.D., Professor and Chairman. Department of Anesthesiology, UCLA School of Medicine, Los Angeles, CA 90024.

Address all communications to: Chingmuh Lee, M.D., Department of Anesthesiology, UCLA School of Medicine, Los Angeles, CA 90024.

Canad. Anaesth. Soc. J., vol. 24, no. 4, July 1977 
weak, being just barely visible, and limited to the neck and fingers. Simultaneous with the onset of block in the other parts of the body, the left wrist and hand went into forceful spasmodic flexion. Full spasm lasted approximately one minute during which time the wrist could not be passively extended. As the other parts of the body recovered from the flaccid paralysis after approximately five minutes, the left hand gradually relaxed. Subsequently, stimulation of the ulnar nerve with a peripheral nerve stimulator (Block-Aid ${ }^{\infty}$ ) at the wrist, and at the elbow, elicited muscle responses which appeared to be normal.

On follow-up visit, no changes in the sensation or muscle power of the hand was found.

In retrospect the resident anaesthetist recalled seeing the same response to succinylcholine one week previously, that is 23 days after the nerve injury, during induction of anaesthesia for a right carotid endarterectomy.

Case 2. Similar observations were made in a female patient, 40 years of age, who was operated on for recurrent carpal tunnel syndrome with motor and sensory impairment. The exact onset of the disease could not be determined. The contracture from succinylcholine was localized to the area affected by the syndrome.

Case 3. A 55-year-old female was admitted for dorsal fusion of the spine $\left(T_{11}-T_{4}\right)$ because of scoliosis. As an infant she had suffered from poliomyelitis from which she had recovered without neurological sequelae. Physical examination revealed a 20-degree limitation of rotation of the neck. The thenar, the hypothenar, and the 4th interosseous muscles of the right hand were smaller than those of the left hand, being approximately half the expected size. Complete neurological examination disclosed no other deficits except a generalized equivocal depression of the deep tendon reflexes.

After induction of anaesthesia with sodium thiopentone $300 \mathrm{mg}$ intravenously, succinylcholine $60 \mathrm{mg}$ was injected intravenously to facilitate intubation of the trachea. Simultaneous with the usual fasciculation and the onset of flaccid paralysis in the rest of the body, the right hand went into spastic contracture similar to prolonged tetanus such as might be elicited by tetanic stimulation of the ulnar nerve at the wrist. The contracture did not fade and subsided only as the rest of the body regained muscle power.

On consultation the surgeon in attendance concurred that the patient probably had a subclinical nerve injury resulting from cervical spondylitis. Repeat neurological examination post-operatively confirmed the absence of signs or symptoms of neurological deficits other than the apparent muscle atrophy of the right hand described above. The conduction velocity of the right ulnar nerve from the elbow to the wrist was $61 \mathrm{~m} / \mathrm{sec}$, which bordered on the lower limit of normal.

\section{Discussion}

Denervation leads to dystrophy of skeletal muscle. The dystrophic muscle responds to depolarizing agents in a manner different from the normal muscle by increased potassium efflux, ${ }^{5-7}$ increased sensitivity, ${ }^{7,8}$ and change of neuromuscular block $^{2-4,7,9}$ from flaccid to spastic paralysis. The spastic response to succinylcholine and decamethonium is rarely seen clinically. It is shared by the normal 
avian muscle and mammalian extraocular muscle, ${ }^{10}$ by muscle of some patients with malignant hyperthermia, ${ }^{11}$ myotonia dystrophica, and myotonia congenita, ${ }^{2,12}$ and by the denervated levator palpebrae superioris which is normally a sympathetically innervated smooth muscle. ${ }^{9}$

Previous clinical reports have not established the amount of nerve injury required to produce a spastic muscular response. Focal contracture induced by succinylcholine in patients with no prior symptoms of nerve injury has not been described before. While the outcome of nerve transection is well known, the time course of the abnormal response to partial injury of the nerve is not clear. Each of the three cases described herein illustrates occurrence of succinylcholineinduced focal contracture following a motor nerve injury of different extent and time course, that is acute, chronic and subclinical chronic. In Case 1, the contracture was produced twice, 23 days and 30 days after an acute nerve injury. The timing fits the time course of denervation hyperkalaemia. ${ }^{7}$

Our observation also suggests that the force of the spastic muscular response to succinylcholine, the extent of involvement and the time course may be valuable in diagnosis and monitoring of the nerve injury. The muscle may continue to respond abnormally as long as partial degeneration continues, until the denervated muscle fibers either degenerate completely, thus becoming unable to contract, or recover to react normally, depending on whether they become re-innervated. For testing purposes, therefore, regional use of small doses of succinylcholine may be considered.

\section{SUMMARY}

Focal muscle contracture in the limb following sytemic administration of depolarizing neuromuscular blocking agents have been demonstrated experimentally with transection or crush injury of the nerve, but has rarely been observed clinically in patients with partial peripheral nerve injury. Three cases of spastic response in the hand and wrist are described in patients with subclinical chronic, subacute, and acute nerve injury, to document the occurrence of this phenomenon under various circumstances.

\section{REFERENCES}

1. Ghonert, G.A., Lambert, E.H., \& Theye, R.A. The response of denervated skeletal muscle to succinylcholine. Anesthesiology 39:13-22 (1973).

2. ORNDAHL, G. Myotonic human musculature: stimulation with depolarizing agents II. A clinico-pharmacological study. Acta. Med. Scand. 172: 753-765 (1962).

3. BRIM, V.D. Denervation supersensitivity: the response to depolarizing muscle relaxants. Brit. J. Anaesth. 45: 222-226 (1973).

4. Walts, L. Complications of muscle relaxants. Muscle relaxants. Edited by R.L. Katz. Amsterdam-London-New York, Exerpta Medica (1975).

5. Cooperman, L.H., Stopel, G.E., \& KenNell, E.M. Massive hyperkalemia after administration of succinylcholine. Anesthesiology 32:161-164 (1970).

6. Kendig, J.J., Bunker, J.P., \& Endow, S. Succinylcholine-induced hyperkalemia: effects of succinylcholine on resting potentials and electrolyte distributions of nomal and denervated muscle. Anesthesiology 36: 132-137 (1972).

7. Gronert, G.A. \& Theye, R.A. Patho-physiology of hyperkalemia induced by succinylcholine. Anesthesiology 43: 89-99 (1975).

8. Axelsson, J. \& ThEsLefF, S. A study of supersensitivity in denervated mammalian skeletal muscle. I. Physiol. 147: 178-193 (1959). 
9. Marshall, M. Action of suxamethonium on ptosis due to third-nerve palsy. Brit. Med. J. 2: 1116-1117 (1964).

10. Eakins, K.E. \& Katz, R.L. Response of the medial rectus muscle of the cat to succinylcholine. Nature 207: 1398-1398 (1965).

11. Ryan, J.F. \& Papper, E.M. Malignant fever during and following anesthesia. Anesthesiology 32: 196-201 (1970).

12. CopY, J.R. Muscle rigidity following administration of succinylcholine. Anesthesiology 29: $159-162$ ( 1968 ). 